\title{
Synaptic Localization of Nitric Oxide Synthase and Soluble Guanylyl Cyclase in the Hippocampus
}

\author{
Alain Burette, ${ }^{1}$ Ulrike Zabel, ${ }^{2}$ Richard J. Weinberg, ${ }^{1}$ Harald H. H. W. Schmidt, ${ }^{3}$ and Juli G. Valtschanoff ${ }^{1}$ \\ ${ }^{1}$ Department of Cell and Developmental Biology, University of North Carolina, Chapel Hill, North Carolina 27599, \\ ${ }^{2}$ Department of Pharmacology and Toxicology, University of Würzburg, 97078 Würzburg, Germany, and ${ }^{3}$ Rudolf- \\ Buchheim-Institute for Pharmacology, D-35392 Giessen, Germany
}

Functional evidence suggests that nitric oxide released from CA1 pyramidal cells can act as a retrograde messenger to mediate hippocampal long-term potentiation, but the failure to find neuronal nitric oxide synthase (NOS-I) in the dendritic spines of these cells has cast doubt on this suggestion. We hypothesized that NOS-I may be in spines but in a form inaccessible to antibody when using standard histological fixation procedures. Supporting this hypothesis, we found that after a weak fixation protocol shown previously to enhance staining of synaptic proteins, CA1 pyramidal cells exhibit clear immunoreactivity for NOS-I. Confocal microscopy revealed that numerous dendritic spines in the stratum radiatum contained the NR2 subunit of the NMDA receptor and the adaptor protein postsynaptic density-95, and a subset of these spines also contained NOS-I. Quantitative studies showed that only $~ 8 \%$ of synaptic

Long-term potentiation (LTP) in the stratum radiatum of the CA1 field of the hippocampus requires concurrent presynaptic activity and postsynaptic calcium entry via NMDA receptors (Bliss and Collingridge, 1993; Nicoll and Malenka, 1995). The increased efficacy of potentiated synapses presumably involves local biochemical changes. Accumulating evidence demonstrates that changes in postsynaptic AMPA receptors contribute to LTP (Malenka and Nicoll, 1999; Malinow et al., 2000; Soderling and Derkach, 2000; Sheng and Lee, 2001). However, increased efficacy of presynaptic transmitter release may also contribute to LTP (Stevens and Wang, 1994; Malgaroli et al., 1995; Choi et al., 2000; Ganguly et al., 2000; Zakharenko et al., 2001). If postsynaptic $\mathrm{Ca}^{2+}$ entry can increase transmitter release, a postsynaptically generated message must act retrogradely at a presynaptic locus. Of the various molecules proposed as retrograde messengers in CA1 pyramidal neurons (Bazan et al., 1997; Schuman, 1997), perhaps the best known candidate is nitric oxide (NO) (Holscher, 1997; Haley, 1998; Prast and Philippu, 2001).

Several laboratories have shown that NO may contribute to hippocampal LTP, at least under certain experimental conditions (Arancio et al., 1996; Haley et al., 1996; Haley, 1998; Hawkins et al., 1998; Zorumski and Izumi, 1998). NO is generated by the

\footnotetext{
Received March 29, 2002; revised Aug. 9, 2002; accepted Aug. 9, 2002.

This work was supported by National Institutes of Health Grant NS39444 (R.J.W.) and by the Deutsche Forschungsgemeinschaft (Collaborative Research Grant 547/ C7) (H.H.H.W.S.). We thank K. Phend for histological support and A. Rustioni for critique of this manuscript.

Correspondence should be addressed to Alain Burette, Department of Cell and Developmental Biology, CB \#7090, University of North Carolina, Chapel Hill, NC 27599. E-mail: alain_burette@med.unc.edu.

Copyright (C) 2002 Society for Neuroscience 0270-6474/02/228961-10\$15.00/0
}

puncta (identified by synaptophysin staining) were associated with NOS-I, and $\sim 9 \%$ contained the $\beta$ subunit of soluble guanylyl cyclase (sGC), a major target of NO. However, the majority of NOS-I-positive synaptic puncta was associated with sGC and vice versa. Postembedding immunogold electron microscopy showed that NOS-I concentrates just inside the postsynaptic plasma membrane of asymmetric axospinous synapses in the stratum radiatum of CA1, whereas $\mathrm{sGC} \beta$ concentrates just inside the presynaptic membrane. Together, these findings support the possibility that $\mathrm{NO}$ may act as a retrograde messenger to help mediate homosynaptic plasticity in a subpopulation of synapses in the stratum radiatum of CA1.

Key words: NOS; retrograde messenger; long-term potentiation; sGC; PSD-95; NR2

oxidation of arginine, a reaction catalyzed by nitric oxide synthase (NOS) (Moncada et al., 1991; Bredt and Snyder, 1994). NOS isoforms normally found in the brain include the calciumdependent enzymes NOS-I (or nNOS, the neuronal isoform) and NOS-III (or eNOS, the endothelial isoform) (Forstermann et al., 1991). NOS-III is found in the vascular endothelium; it was reported also in hippocampal neurons (Dinerman et al., 1994; O'Dell et al., 1994), but failure to confirm the finding (Chiang et al., 1994; Weinberg et al., 1994) has led many to doubt this conclusion. NOS-I is expressed by hippocampal interneurons, although its presence in CA1 pyramidal cells remains somewhat controversial (Bredt et al., 1991; Vincent and Kimura, 1992; Valtschanoff et al., 1993a; Dun et al., 1994; Wendland et al., 1994; Lin and Totterdell, 1998). Biochemical data show that NOS-I can bind to the postsynaptic scaffold molecule PSD-95, forming a complex with the NMDA receptor (Brenman et al., 1996; Christopherson et al., 1999). Consistent with these in vitro data, several laboratories have reported ultrastructural evidence for NOS-I at axospinous synapses (Aoki et al., 1993; Faber-Zuschratter and Wolf, 1994; Faber-Zuschratter et al., 1996; Aoki et al., 1997; Sancesario et al., 2000; Valtschanoff and Weinberg, 2001).

A principal mediator of signal transduction by $\mathrm{NO}$ is soluble guanylyl cyclase (sGC) (Zabel et al., 1998; Denninger and Marletta, 1999; Koesling, 1999; Wedel and Garbers, 2001), also implicated in some forms of LTP (Boulton et al., 1995; Son et al., 1998; Lu et al., 1999; Arancio et al., 2001). sGC comprises an $\alpha$ subunit and a smaller heme-containing $\beta$ subunit. Heterodimers are activated by NO binding to the heme moiety, whereas homodimers exhibit little or no cGMP synthetic activity, even in the presence of NO (Zabel et al., 1999). Despite its role as a principal 
Table 1. Primary antibodies used in the study

\begin{tabular}{|c|c|c|c|c|}
\hline Protein & Source & Antibody & Host & Characterized in \\
\hline NOS-I & Zymed & Z-RNN & Rabbit & \\
\hline $\operatorname{sGC}(\beta 1$ subunit $)$ & H.H.H.W. Schmidt & sa2934 Gua2 & Rabbit & Zabel et al., 1998, 1999 \\
\hline Synaptophysin & Sigma & Clone SVP-38 & Mouse & Devoto and Barnstable, 1989 \\
\hline $\mathrm{NR} 2 \mathrm{~A} / \mathrm{B}$ & Chemicon & AB1548 & Rabbit & Petralia et al., 1994 \\
\hline PSD-95 & Transduction Laboratories & Clone 16 & Mouse & Derek et al., 1999 \\
\hline
\end{tabular}

target for NO, little is yet known about the distribution of sGC in the brain (Burgunder and Cheung, 1994; Burette et al., 2001a; Ibarra et al., 2001)

Using light microscopic immunocytochemical methods optimized to detect synaptic antigens, we here report that NOS-I and sGC $\beta$ associate with each other at a subpopulation of synaptic puncta. Using postembedding immunogold electron microscopy in the stratum radiatum of CA1, we find that NOS-I lies within the postsynaptic density of asymmetric axospinous synapses (consistent with previous studies), whereas $\mathrm{sGC} \beta$ concentrates in axon terminals; moreover, the anatomical relationship between presynaptic sGC and postsynaptic NOS is spatially precise. These results provide neuroanatomical support for the hypothesis that NO can act as a synapse-specific retrograde messenger in CA1.

\section{MATERIALS AND METHODS}

Antisera. Antibodies used in this study are listed in Table 1 . We used a $\beta_{1}$-specific antibody to probe for sGC. $\beta_{1}$ is the predominant $\beta$ subunit of sGC in the brain; because homodimers are enzymatically inactive (Zabel et al., 1998), and because a linear relationship is observed between the amounts of $\alpha_{1}$ and $\beta_{1}$ in different brain regions (Ibarra et al., 2001), we consider $\beta_{1}$ to be a suitable proxy for overall levels of sGC enzyme. We initially considered the NOS-I antibody likely to be specific because its general pattern of staining resembled that for a better characterized antibody and for staining with NADPH diaphorase (NADPHd), a histochemical marker for NOS (Dawson et al., 1991; Hope et al., 1991; Schmidt et al., 1992). To provide more compelling evidence for its specificity, we compared immunolabeling on tissue from NOS-I knockout mice and genetically matched controls. The other antibodies used in this study are well characterized and commercially available (Valtschanoff et al., 1999; Burette et al., 2001a).

Tissue preparation. All procedures related to the care and treatment of animals were in accordance with institutional and National Institutes of Health guidelines. Ten male Sprague Dawley rats (200-350 gm; Charles River, Raleigh, NC) and eight male mice (7-10 weeks of age; The Jackson Laboratory, Bar Harbor, ME), including four NOS-I knock-out mice (strain B6129S-Nos1 ${ }^{\text {tmlPlh }}$ ) and four matched controls (strain B6129SF2/J), were used for this study. After inducing deep anesthesia with sodium pentobarbital $(60 \mathrm{mg} / \mathrm{kg}$, i.p.), rats were intracardially perfused with heparinized saline, followed by $500 \mathrm{ml}$ of fixative; for mice, we used $25-50 \mathrm{ml}$ of fixative. For LM, some animals were fixed according to standard protocols, using $4 \%$ freshly depolymerized paraformaldehyde in phosphate buffer $(\mathrm{PB} ; 0.1 \mathrm{M}, \mathrm{pH} 7.4)$; brains were removed and postfixed overnight at $4^{\circ} \mathrm{C}$ in the same fixative. To assess whether limited antibody access consequent to aldehyde cross-linking may influence results, we tested the effects of weak fixation, perfusing five rats and two mice with $1 \%$ paraformaldehyde, followed by a saline flush. For EM, animals were fixed with a mixture of $4 \%$ paraformaldehyde and $0.1-2 \%$ glutaraldehyde in PB. Brains were sectioned at $40-60 \mu \mathrm{m}$ on a Vibratome and collected in cold PB.

LM immunocytochemistry. For immunoperoxidase, free-floating sections were permeabilized with $50 \%$ ethanol for $30 \mathrm{~min}$ and treated for 30 min with $3 \% \mathrm{H}_{2} \mathrm{O}_{2}$ in $\mathrm{PBS}(0.1 \mathrm{M}, \mathrm{pH} 7.4)$ to quench endogenous peroxidase activity. They were then preincubated in $10 \%$ normal donkey serum (to block secondary antibody binding sites). Sections were incubated in primary antibody (NOS-I or $\mathrm{sGC} \beta ; 1: 2000$ ) overnight on a shaker at room temperature and then for $3 \mathrm{hr}$ in biotinylated anti-rabbit antibody (1:200; Vector Laboratories, Burlingame, CA) and for $1 \mathrm{hr}$ in ExtrAvidin-peroxidase (1:5000; Sigma, St. Louis, MO). Peroxidase was histochemically visualized with diaminobenzidine. Processed sections were mounted on gelatin-coated slides and coverslipped with DPX mountant (BDH Chemicals, Poole, UK).

For immunofluorescence, sections were incubated overnight in primary antibody (NOS-I or sGC $\beta ; 1: 1000$ ). Immunoreactivity was visualized by donkey IgG, conjugated to FITC (Jackson ImmunoResearch, West Grove, PA). Sections were mounted on gelatin-coated slides and directly coverslipped with Vectashield (Vector Laboratories) for viewing under Nomarski illumination. To control for method specificity, some sections were processed as above, except that primary or secondary antibodies were omitted. In all such cases, staining was barely detectable or completely absent.

Multiple immunofluorescence labeling. Tyramide signal amplification (TSA) was used to permit multiple labeling with primary antibodies from a single species (Shindler and Roth, 1996). Fluorescent staining with the first primary antibody was enhanced with TSA, and conventional fluorescent staining was then performed with the second primary antibody. We used the first primary antibodies at a concentration so low that antigen consistently failed to be revealed by a conventional fluorophoreconjugated secondary antibody (donkey anti-rabbit IgG conjugated to FITC; 1:200 for $3 \mathrm{hr}$; Jackson ImmunoResearch) but was still clearly detectable with TSA. After overnight incubation in primary antibody (NOS-I, 1:30,000; $\operatorname{sGC} \beta, 1: 15,000$; or NR2, 1:10,000), sections were reacted for $2 \mathrm{hr}$ at room temperature with biotinylated secondary antibody (1:200; Jackson ImmunoResearch). Biotin was revealed by FITC conjugated to tyramide (Renaissance TSA direct kit; DuPont NEN, Wilmington, DE), according to the manufacturer's recommendation. The second primary antibodies were then applied overnight (NOS-I or sGC; 1:1000). Immunoreactivity was visualized by donkey anti-rabbit antibody conjugated to Cy3 (Jackson ImmunoResearch). For triple labeling, the third primary antibody (raised in a different species than the first two primary antibodies) was applied overnight [PSD-95 (1:500) or synaptophysin (1:1000)] and visualized by a secondary antibody conjugated to Cy5 (Jackson ImmunoResearch). All secondary antibodies were multiple labeling grade and had been extensively preadsorbed with normal serum from other species to prevent inadvertent cross-reaction.

Controls. As emphasized by Shindler and Roth (1996), several control procedures are necessary to obtain reliable multiple labeling with the TSA method. Omission of primary or secondary antibodies resulted in the lack of specific staining in the corresponding channel. Substitution of preimmune normal serum for primary antibody led to a very weak Nissl-like pattern of staining. To control for possible cross-reaction between the first primary antibody and the second secondary antibody, the second primary antibody was omitted. In such cases, no staining was observed on the channel corresponding to the second secondary antibody. Moreover, we obtained identical results when the order of the two primary antibodies was reversed.

Visualization of cell processes. To define the relationship between cellular morphology and immunostaining, we used the lipophilic dye 4-(4-(dihexadecylamino)styryl)- $N$-methyl pyridinium iodide (DiA) (Molecular Probes, Eugene, OR), which infiltrates the plasma membrane, labeling even the finest neuronal processes. DiA crystals were applied with a micropipette directly to immunostained sections set gently on top of an agar-filled Petri dish. The dish was then covered and stored at $4{ }^{\circ} \mathrm{C}$ for 24-72 hr. Sections were mounted on slides and coverslipped with Vectashield.

Microscopy and data analysis. Sections were examined with a Leitz DMR (Wetzlar, Germany) microscope under bright field, Nomarski, or epifluorescence illumination. Fluorescent images were acquired with a cooled charge-coupled device (CCD) camera (Princeton Instruments, Trenton, NJ) coupled to a Macintosh computer. IP Lab software (Scanalytics, Fairfax, VA) was used for image acquisition and initial processing. 
For optimal resolution of thick sections, images were acquired with a Leica TCS confocal microscope. By following optical sections through $z$-axis stacks, it was possible to assess continuity of processes through the thickness of a tissue section.

Postembedding electron microscopy. For postembedding immunolabeling, sections from three rats, fixed with $2 \%$ paraformaldehyde and $2 \%$ glutaraldehyde, were processed for osmium-free embedment in EponSpurr resin according to the method of Phend et al. (1995). Thin $(\sim 100$ $\mathrm{nm})$ sections were collected on nickel mesh grids and processed for immunogold labeling as described previously (Phend et al., 1992, 1995). Briefly, after treatment with $4 \%$ para-phenylenediamine in Tris-buffered saline (TBS/T; $0.1 \mathrm{~m}$ Tris, $\mathrm{pH}$ 7.6, with $0.005 \%$ Tergitol Nonidet P-10), grids were incubated overnight at $37^{\circ} \mathrm{C}$ in the primary antibody. Grids were then transferred to TBS/T, $\mathrm{pH} 8.2$, incubated for $1 \mathrm{hr}$ in the secondary antibody conjugated to $10 \mathrm{~nm}$ gold particles (1:15 in TBS/T, pH 8.2; British BioCell; Ted Pella, Redding, CA), and counterstained with uranyl acetate and Sato's lead. Grids were examined on a Philips Tecnai 12 electron microscope (FEI, Hillsboro, OR) at $80 \mathrm{kV}$ accelerating voltage.

For quantitative study, two thin sections from each of the three rats, labeled with $10 \mathrm{~nm}$ gold particles, were examined. Digital images of asymmetric synapses that had clearly defined synaptic membranes and were labeled with at least one gold particle within $100 \mathrm{~nm}$ of the postsynaptic membrane were randomly acquired at $\times 30,000$ magnification using a CCD camera (Gatan, Pleasanton, CA) attached to the electron microscope. Locations of gold particles were measured with Scion Image software version 4.0 (Scion, Frederick, MD). To define "axodendritic" position, the distance between the center of each gold particle and the outer leaflet of the postsynaptic membrane was measured. The distance from each end of the active zone to a line drawn perpendicular to the synaptic membrane and running through the center of the particle was used to determine the tangential position of each particle with respect to the synapse; we used these data to compute the normalized lateral position, with 0 corresponding to the center of the active zone and 1 to its edge (Valtschanoff and Weinberg, 2001).

To study colocalization of NOS-I and $\operatorname{sGC} \beta$, serial sections were collected on successive grids and stained for the two antigens, and then corresponding regions of each grid were examined. To study colocalization on the same thin section, the two antigens were labeled with two sizes of immunogold, using the same protocol as for single labeling [NOS-I (1:500) and sGC $\beta$ (1:100)]. Because both antibodies were raised in the same species, we applied hot formaldehyde fumes to the grids $\left(80^{\circ} \mathrm{C}\right.$ for $\left.1 \mathrm{hr}\right)$ to denature the first primary antibody and minimize cross-reaction (Phend et al., 1992). When primary antiserum was omitted as a control, virtually no gold particles could be detected on the section; when normal serum was substituted for immune serum, sparse gold particles were scattered across the section.

Digital postprocessing. We used Adobe PhotoShop version 5 (Adobe Systems, San Jose, CA) and Corel Draw version 10 (Corel, Ontario, Canada) to sharpen images, balance colors, adjust brightness and contrast, and compose final plates. Specific regions of an acquired image were not selectively processed; all adjustments were applied to the entire field.

\section{RESULTS}

\section{Specificity of the NOS-I antibody}

Our laboratory has encountered difficulties using NOS-I antibodies for postembedding gold immunocytochemistry; we presume that this reflects idiosyncrasies of the NOS-I molecule and its epitope exposure after fixation and embedment. After extensive trials, we found that the primary antibody supplied by Zymed (South San Francisco, CA) (Table 1) performs particularly well. That the antibody was specific seemed likely, because the overall pattern of staining with LM resembled that seen with NADPHd staining and with better-characterized antibodies (Schmidt et al., 1992). To provide more conclusive evidence, we performed immunocytochemistry on material from NOS-I knock-out mice, run in parallel with material from control mice and rats. For each light and electron microscopic immunocytochemical procedure reported below, staining in the knock-out mice was extremely weak and exhibited a "background" pattern unrelated to that seen for

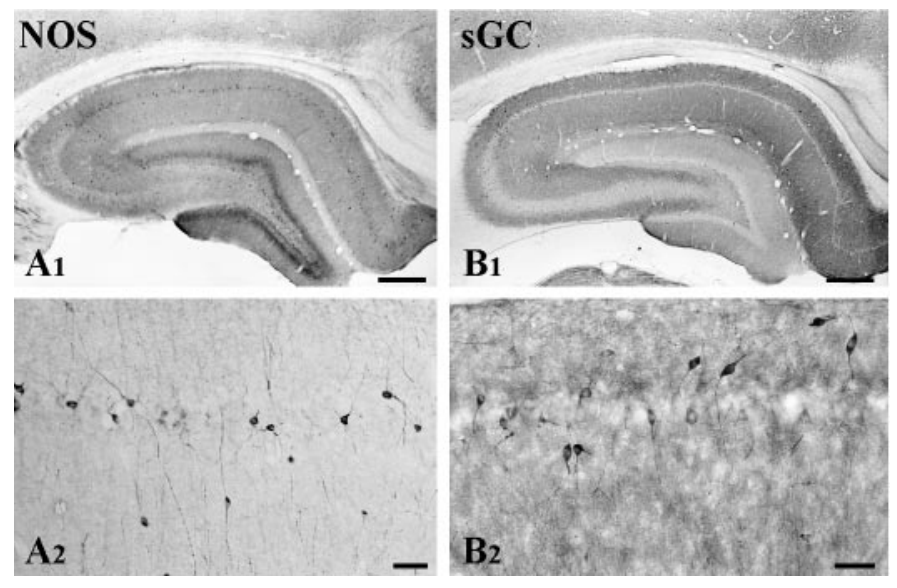

Figure 1. Immunostaining for NOS-I and sGC $\beta$ after fixation with $4 \%$ paraformaldehyde. $A_{1}$, Staining for NOS-I is in scattered cells and is denser in the dentate hilus. Neuropil staining is prominent in the dentate molecular layer and in the stratum radiatum of Ammon's horn. $A_{2}, \mathrm{~A}$ population of nonpyramidal neurons in CA1 stain intensely, in contrast to unstained somata of pyramidal cells (pyramidal cell layer in the middle, stratum radiatum toward the bottom). $B_{1}$, Staining for $\mathrm{sGC} \beta$ is intense in scattered cells and most numerous in CA2; diff use immunostaining is seen in the neuropil of Ammon's horn. $B_{2}$, In CA1, pyramidal cells are unstained or very weakly stained, whereas some nonpyramidal cells are strongly immunopositive. Scale bars: $A_{1}, B_{1}, 500 \mu \mathrm{m} ; A_{2}, B_{2}, 50 \mu \mathrm{m}$.

controls (data not shown). Therefore, we conclude that this antibody specifically recognizes NOS-I when used according to our protocols.

\section{LM distribution of NOS and SGC after standard fixation}

After fixation with $4 \%$ paraformaldehyde, the distribution of NOS-I throughout the hippocampus was as reported previously using both immunocytochemistry and histochemistry for NADPHd (Vincent and Kimura, 1992; Valtschanoff et al., 1993a; Dun et al., 1994). At low magnification, diffuse staining extended throughout the hippocampus, most prominent in the inner third of the molecular layer of the dentate gyrus, and sparing the stratum lacunosum moleculare (Fig. $1 A_{1}$ ). Immunopositive cells were most numerous in the subiculum and in the hilar region of the dentate. In CA1, intense somatodendritic immunostaining was observed in a small number of interneurons scattered throughout the pyramidal layer, extending also into other layers (Fig. $1 A_{2}$ ). In contrast, somata of pyramidal neurons were immunonegative or very weakly stained. In the stratum radiatum, intensely immunoreactive puncta could be seen, especially with immunofluorescence; we interpret these puncta as dendritic branches cut in cross section (see below).

At low magnification, the overall pattern of $\mathrm{sGC} \beta$ staining differed from that for NOS-I. Staining was strongest in the subiculum and was prominent also in the neuropil of Ammon's horn, sparing the pyramidal cell layer and granule cell layer of the dentate (Fig. 1 $B_{1}$ ). At higher magnification, it was clear that pyramidal and granule cells were unstained, although a small number of intensely sGC $\beta$-positive neurons was randomly scattered throughout CA1, among others that stained more weakly (Fig. $1 B_{2}$ ). The pattern of staining was somatodendritic, sparing the nucleus. Based on their morphology, most of these cells were likely to be local circuit neurons. Double immunofluorescence demonstrated that a few of these sGC-positive cells were also immunopositive for NOS-I (data not shown). Diff use staining was seen in the neuropil. 

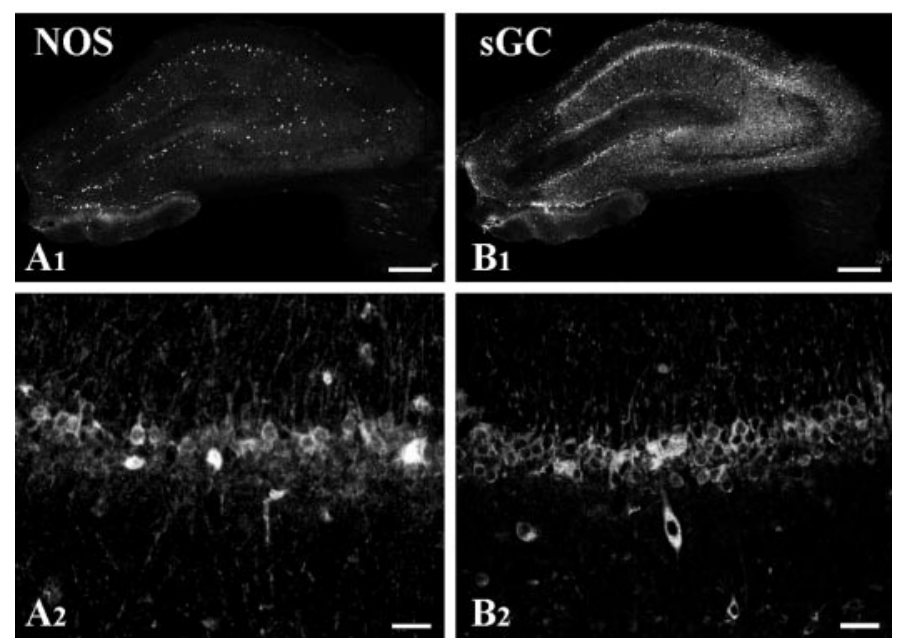

Figure 2. Immunostaining for NOS-I and $\mathrm{sGC} \beta$ after fixation with $1 \%$ paraformaldehyde. $A_{1}$, As for material fixed with $4 \%$ paraformaldehyde, a few nonpyramidal neurons scattered throughout the hippocampal formation were intensely immunopositive. $A_{2}$, Higher magnification revealed immunostaining also in the cytoplasm of numerous CA1 pyramidal cells, at variance with the image seen after stronger fixation (Fig. $1 A_{2}$ ). $B_{1}$, Scattered cells were strongly immunopositive for sGC $\beta$. At low magnification, the pyramidal cell layer of CA1 stood out as diffusely immunopositive, at variance with the image seen after stronger fixation. $B_{2}$, Higher magnification showed immunostaining for $\mathrm{sGC} \beta$ in the cytoplasm of a large number of CA1 pyramidal cells. Scale bars: $A_{1}, B_{1}, 500 \mu \mathrm{m} ; A_{2}, B_{2}$, $50 \mu \mathrm{m}$.

\section{LM distribution of NOS and SGC after weak fixation}

Previous results suggest that NOS-I may be difficult to detect after standard formaldehyde fixation protocols (Wendland et al., 1994; Gonzalez-Hernandez et al., 1996). This may reflect denaturation of essential epitopes; alternatively, cross-linking of proteins associated with standard fixation protocols may limit antibody access, especially within the protein-rich PSD, leading to spurious negative results (cf. Valtschanoff et al., 2000). Therefore, it seemed possible that many synapses might contain NOS-I that could not be detected by standard methods. Moreover, the immunostaining for $\mathrm{sGC} \beta$ was at variance with in situ results suggesting that pyramidal neurons in CA1 express appreciable amounts of this protein (Matsuoka et al., 1992; Gibb and Garthwaite, 2001). Therefore, we performed immunostaining on weakly fixed material (from rats perfused with $1 \%$ paraformaldehyde).
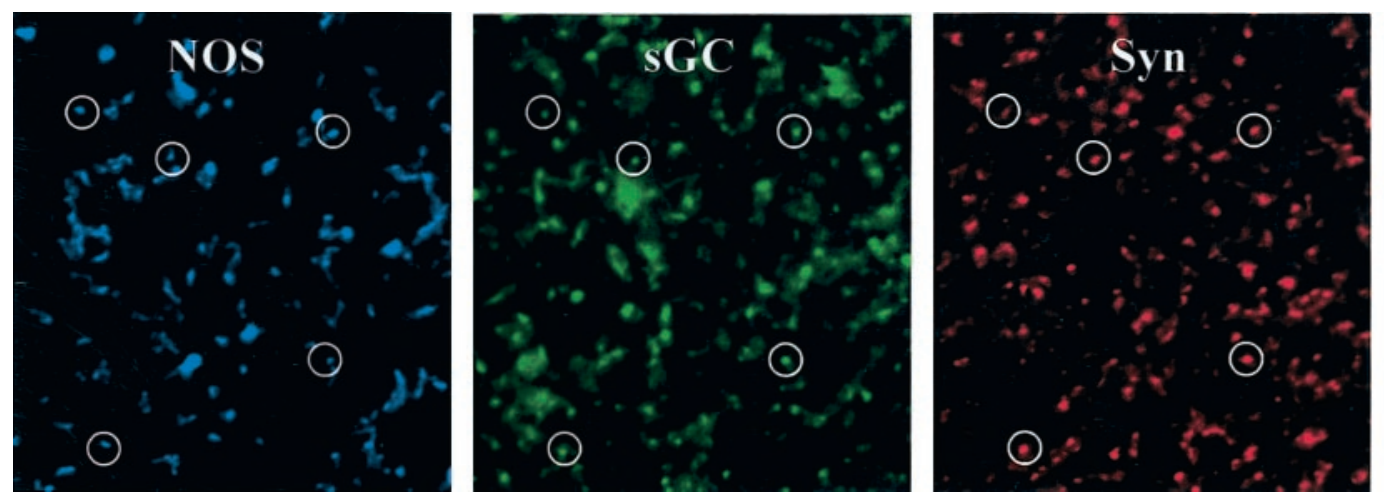

Figure 3. Triple immunofluorescence for NOS-I (blue), $\mathrm{sGC} \beta$ (green), and the presynaptic marker synaptophysin (Syn, red), in the stratum radiatum of CA1. Examples of puncta double stained for $\mathrm{sGC} \beta$ and synaptophysin, apposed to puncta stained for NOS-I, are circled. Contrast is enhanced in the triple-labeled panel (right) to facilitate identification of multiple labeling. Scale bar, $10 \mu \mathrm{m}$.
To assess the distribution of NOS and sGC at synapses, we performed triple immunolabeling for NOS-I, sGC, and synaptophysin. Numerous puncta immunoreactive for NOS-I and sGC $\beta$ were observed in the stratum radiatum (Fig. 3). Punctate staining was variable in intensity and strongest in profiles likely to be transversely cut dendrites of interneurons. Consistent with this interpretation, only a weak relationship was detected between the brightest puncta and the presynaptic marker synaptophysin. In contrast, a close relationship was observed between many of the more weakly immunoreactive puncta and synaptophysin, suggesting that both NOS-I and sGC $\beta$ are present at synapses (Fig. 3, circles).

We examined this triple-labeled material under conditions of optimal resolution (confocal microscopy using a small pinhole and high numerical aperture oil immersion objective), attempting to distinguish puncta that overlapped in two channels, from puncta that were adjacent. For NOS-I, 19\% (13 of 75) of synaptophysin-related puncta were judged to overlap the synaptophysin puncta, whereas $81 \%$ (62 of 75 ) were judged to lie adjacent; in contrast, for sGC $\beta, 72 \%$ (65 of 89) of synaptophysinrelated puncta were judged to overlap the synaptophysin, whereas only $28 \%$ (24 of 89 ) lay adjacent (Table 2). Thus, sGC $\beta$-positive puncta were significantly more likely to overlap synaptophysin puncta than were NOS-I puncta $(p<0.01$; paired two-sided $t$ test). Although the limited resolution of light microscopy prevents definite conclusions, these data are consistent with the hypothesis that sGC concentrates in axon terminals, whereas NOS-I concentrates in postsynaptic densities. Quantitative examination revealed that $8 \%$ of synaptophysin-

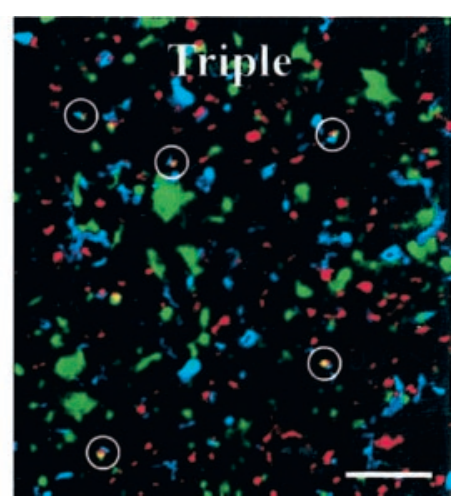

As with standard fixation (4\% paraformaldehyde), NOS-I im-
munoreactivity in CA1 was intense in scattered interneurons (Fig. $2 A_{1}$ ). However, in contrast to the distribution after standard fixation, weak to moderate immunoreactivity was also observed
consistently in the somata of numerous pyramidal neurons (Fig. $2 \mathrm{~A}_{2}$ ), extending into dendrites. The difference in sGC $\beta$ immunowere intensely immunopositive (Fig. $2 B_{1}$ ), but in contrast to the "negative staining" after standard fixation, the pyramidal cell layer of CA1 stood out as immunopositive after weak fixation, reflecting a moderate level of immunostaining in pyramidal cells (Fig. $2 \mathrm{~B}_{2}$ ).

\section{LM evidence for synaptic immunostaining after}




\section{Table 2. NOS-I and sGC $\beta$ in synaptophysin-positive puncta \\ Syn+NOS overlapping $19 \% \pm 9(13 / 75)$ \\ Syn+sGC overlapping \\ Syn+NOS adjacent \\ $* * 81 \% \pm 9(62 / 75)$ \\ Syn + s $G C$ adjacent \\ $* 28 \% \pm 10(24 / 89)$ \\ $($ Syn+NOS)/(all Syn) \\ $8 \% \pm 2(75 / 831)$ \\ $(S y n+s G C) /($ all Syn $)$ \\ $9 \% \pm 1(89 / 831)$ \\ $(S y n+N O S+s G C) /(S y n+N O S)$ $* * * 52 \% \pm 6(47 / 75)$ \\ $(S y n+N O S+s G C) /(S y n+s G C)$ $* * * 64 \% \pm 6(47 / 89)$}

Synaptophysin-positive puncta (Syn) were usually adjacent to NOS-positive puncta (left column, upper rows), and usually overlapped sGC puncta (right column). Synaptophysin-positive puncta that overlapped NOS puncta were much more likely to overlap also sGC puncta (left column, lower rows), and vice versa (right column), suggesting a selective synaptic relationship between NOS and SGC. High-resolution confocal images of CA1 from four rats were analyzed (values are means \pm standard errors). Two-sided t-tests were performed, to assess significance of differences between vertically-paired data sets; ${ }^{*} \mathrm{p}<0.05 ;{ }^{* *} \mathrm{p}<0.01 ;{ }^{* * *} \mathrm{p}<0.001$ (paired 2 -sided t-tests; $\mathrm{n}=4$ ).

positive puncta were NOS-I positive, and $9 \%$ of synaptophysinpositive puncta were sGC $\beta$ positive (Table 2). These doublelabeled puncta are likely to be NOS-positive and sGC-positive synapses, respectively. We hypothesized that these two elements of the NO signaling pathway might be specifically related, such that sGC-positive axon terminals are selectively presynaptic to NOS-positive PSDs. Supporting this hypothesis, 52\% of the NOSpositive synaptic puncta also expressed sGC, and $64 \%$ of sGCpositive synaptic puncta also expressed NOS (Table 2). If we restricted consideration to sGC puncta overlapping synaptophysin puncta and NOS puncta adjacent to synaptophysin puncta, the selectivity was even more striking; $74 \%$ of NOS-positive puncta also expressed sGC, and $81 \%$ of sGC-positive puncta also expressed NOS. This suggests that a subpopulation of synapses in the stratum radiatum are biochemically specialized to use the NO-sGC signaling pathway.

To investigate more directly the relationship between NOS-I and $\mathrm{sGC} \beta$ in dendritic spines, we used the lipophilic tracer DiA to label the dendritic plasma membrane of CA1 pyramidal cells. Double immunostaining performed in this material demonstrated that numerous spines in the stratum radiatum contained NOS-I. In many cases, a clear relationship could be seen between NOSpositive spines and adjacent sGC $\beta$-stained puncta (Fig. 4).

NOS-I is preferentially activated by calcium influx through NMDA receptors, at least in cultured neurons (Kiedrowski et al., 1992). This special relationship between NMDA receptormediated calcium influx and NOS-I activation suggests that the receptor may be physically coupled to the enzyme. In view of biochemical evidence that NMDA receptors and NOS-I can be linked together by the adaptor protein PSD-95 (Christopherson et al., 1999; Sattler et al., 1999; Tochio et al., 2000; Valtschanoff
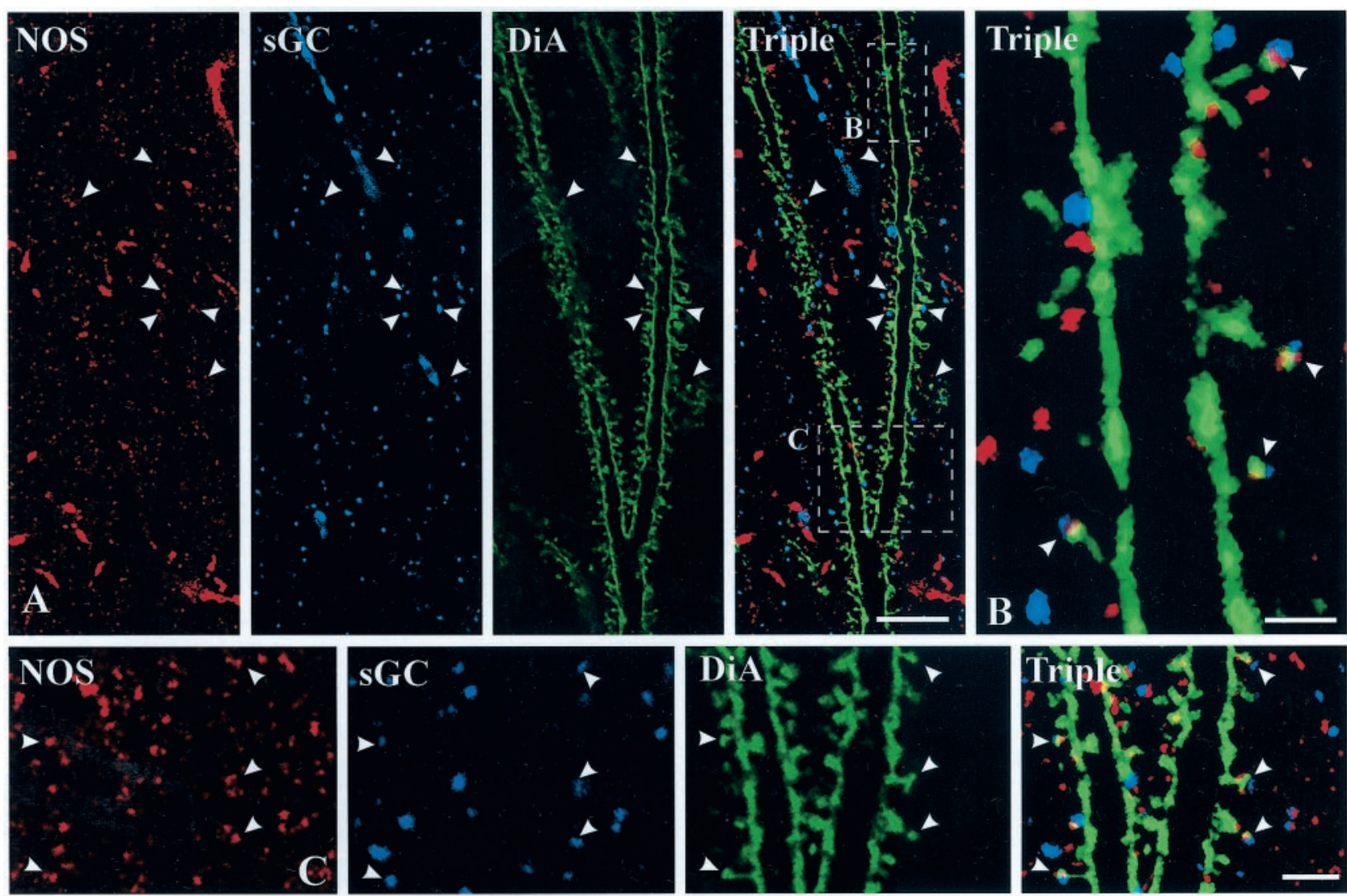

Figure 4. NOS-I and sGC $\beta$ in dendritic spines. The lipophilic dye DiA (green), which stains the entire plasma membrane of scattered CA1 pyramidal neurons, allows appreciation of the relationship of antigen to dendrites and dendritic spines. $A$ (top panel), Low-magnification overview of the relationship of immunostaining for NOS-I (red) and $\mathrm{sGC} \beta$ (blue) with apical dendrites of pyramidal neurons stained with DiA. $B, C$, High-magnification views of boxed areas. Arrowheads point to dendritic spines immunopositive for NOS-I, associated with puncta immunopositive for sGC $\beta$. Scale bars: $A$, $10 \mu \mathrm{m} ; B, 2.5 \mu \mathrm{m} ; C, 2 \mu \mathrm{m}$. 

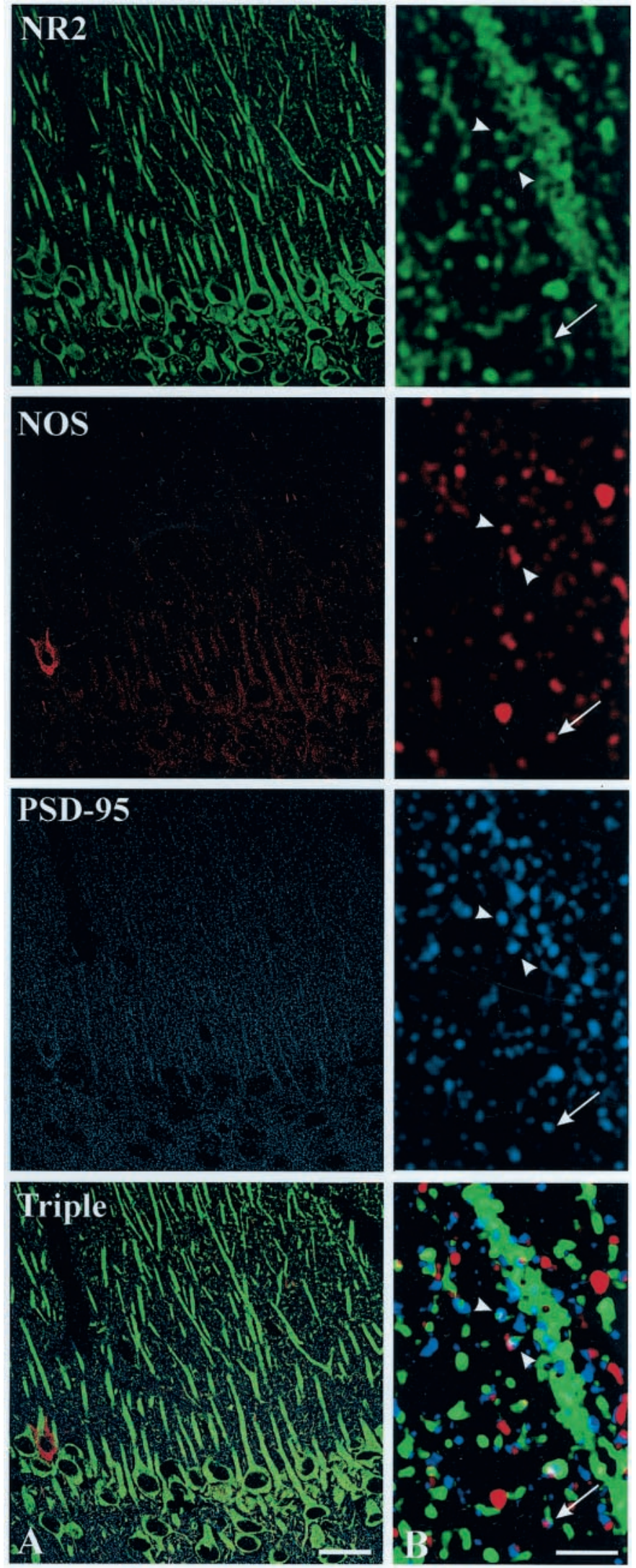

Figure 5. Triple immunofluorescence for NR2 ( green), NOS-1 (red), and PSD-95 (blue). A, CA1 pyramidal cells express all three proteins. NR2 stains somata and proximal dendrites, although puncta in the neuropil are also visible; staining for PSD-95 is almost exclusively punctate, and NOS-I shows an intermediate staining pattern. $B$, High-magnification views of and Weinberg, 2001), and previous evidence from cerebral cortex (Aoki et al., 1998), we wondered whether the three proteins actually colocalize in the hippocampus. Using triple immunostaining, we found that NR2 in the stratum radiatum colocalized with PSD-95 and NOS-I (Fig. $5 A$ ); examination at higher magnification showed that this colocalization was in puncta, which in some cases could be identified as dendritic spines (Fig. 5B).

\section{Ultrastructural distribution of NOS and sGC}

The above data demonstrate a spatial association between NOSI-positive and sGC $\beta$-positive puncta and support the possibility that NOS lies within the PSD at excitatory synapses, immediately postsynaptic to $\mathrm{SGC}$-positive axon terminals, an arrangement that would suggest a role for NO as retrograde messenger. However, to answer this question unequivocally is beyond the limit of resolution of light microscopy, and pre-embedding EM is inherently limited by variable antibody penetration (Griffiths, 1993). To provide optimal spatial resolution and maintain uniform access to antibody, we performed postembedding electron microscopy. A few aspiny dendritic profiles, presumably arising from NOSpositive interneurons, were immunopositive. Immunogold particles coding for NOS-I concentrated over the postsynaptic density of axospinous synapses of asymmetric type (Fig. 6 $\mathrm{A}$ ). In contrast, sGC $\beta$ labeling was concentrated over the presynaptic terminals of asymmetric axospinous synapses (Fig. 6B). Quantitative EM of randomly selected asymmetric synapses in the stratum radiatum confirmed that gold particles coding for NOS-I were predominantly postsynaptic, concentrating just cytoplasmic to the postsynaptic membrane, whereas particles coding for $\mathrm{sGC} \beta$ were predominantly presynaptic, concentrating $\sim 15-25 \mathrm{~nm}$ cytoplasmic to the presynaptic membrane (Fig. 6C).

The distributions of NOS-I and sGC suggest that the two enzymes might be present on the two sides of the same synapses. To test this hypothesis, we examined sections double labeled using two sizes of gold particles. To control for possible crossreactivity (because the two primary antibodies were raised in the same species), we also studied serial single-labeled sections. Despite the vagaries of these methods, we were able to demonstrate NOS-I-positive PSDs postsynaptic to sGC $\beta$-positive terminals, using both techniques (Fig. $6 D-F$ ).

Because postembedding immunogold is thought to provide an unbiased estimate of antigen distribution, these data can be taken to demonstrate that a large fraction of the NOS-I in the general region of the synaptic apposition is intimately associated with the PSD and likewise that a large fraction of the sGC lies very close to the presynaptic active zone. Because most potential antigenic sites are occluded by the plastic resin, postembedding data may suffer from false negatives and are therefore not well suited to determine the quantitative relationship between sGC-positive terminals and NOS-I-positive dendrites. However, in light of the spatially accurate immunogold data, the immunofluorescence data of Table 2 support a precise trans-synaptic relationship between the two proteins.

the material shown in $A$ reveal that some spines visible with NR2 staining label also for both PSD-95 and NOS-I (arrowheads). Triple-stained puncta are also visible in the neuropil (arrow); however, in this material, it is impossible to determine whether these puncta are associated with dendritic spines. Contrast is enhanced in the bottom panel to facilitate identification of multiple labeling. Scale bars: $A, 50 \mu \mathrm{m} ; B, 3 \mu \mathrm{m}$. 

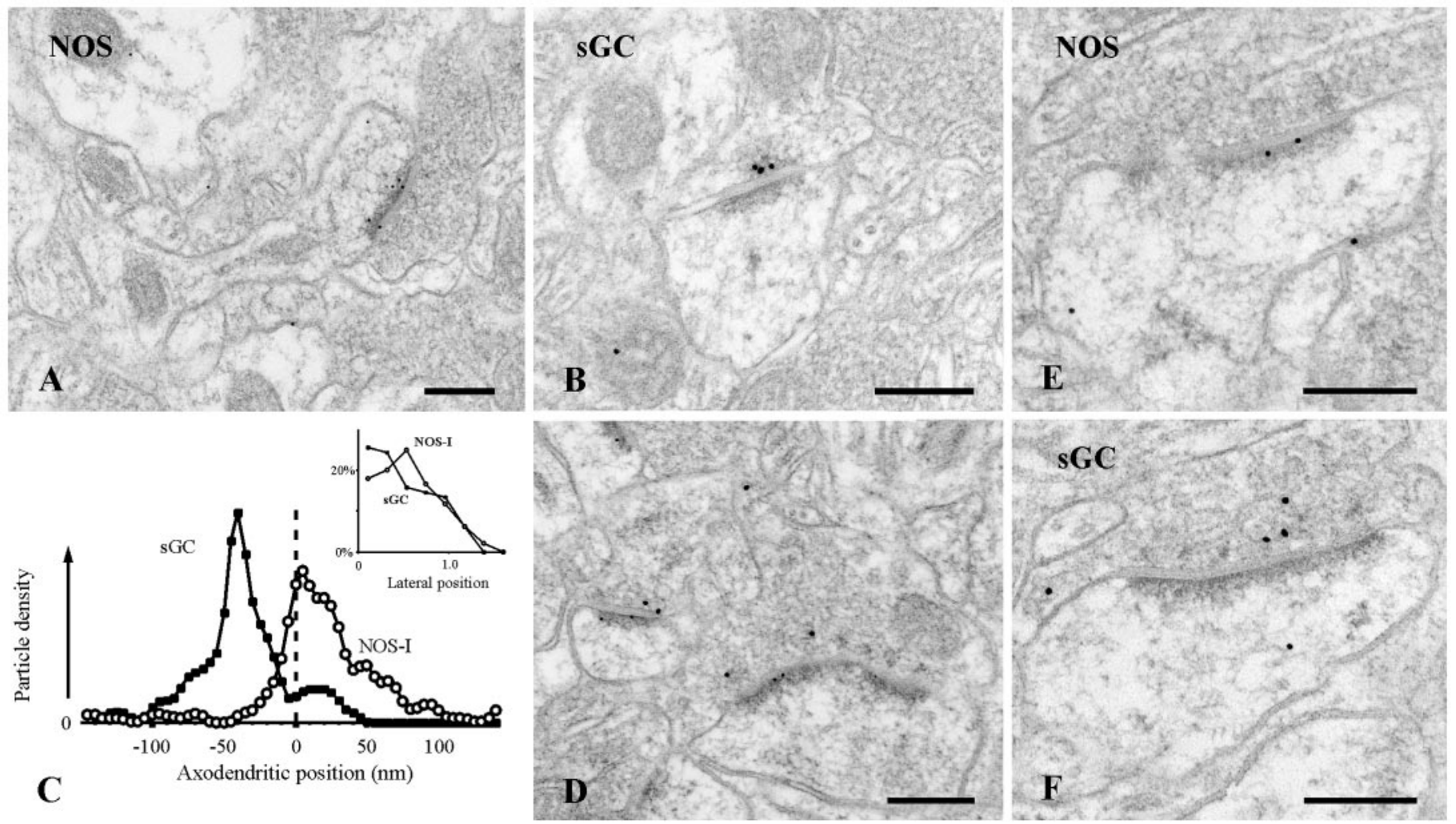

Figure 6. Postembedding immunogold labeling for NOS-I and sGC $\beta$ in the stratum radiatum of CA1. $A$, Synaptic labeling for NOS-I concentrates at the postsynaptic density of an axospinous synapse of asymmetric type. $B$, Labeling for sGC $\beta$ concentrates at the presynaptic active zone. $C$, Positions of 144 gold particles coding for NOS-I and 82 particles coding for sGC $\beta$ within $\pm 150 \mathrm{~nm}$ of the postsynaptic membrane were measured relative to the postsynaptic membrane of randomly sampled synapses in CA1. The axodendritic graph (digitally smoothed) shows that labeling density for NOS-I peaked at the postsynaptic membrane, extending into the postsynaptic profile, whereas labeling for sGC $\beta$ concentrated at the presynaptic membrane. Inset, Labeling close to the plasma membrane concentrated at the synaptic specialization for both antigens. Double immunogold labeling $(D)$ and single labeling on serial sections $(E, F)$ document that NOS-positive PSDs were postsynaptic to sGC $\beta$-positive axon terminals. Scale bars, $0.2 \mu \mathrm{m}$.

\section{DISCUSSION}

Here we confirm previous results on the cellular and subcellular organization of NOS-I, showing with quantitative immunogold methods that this enzyme concentrates at the postsynaptic density of axospinous synapses in the stratum radiatum of CA1. We also show that the sGC, a major target for nitric oxide, concentrates in presynaptic terminals close to the active zone. Finally, we show evidence for a precise trans-synaptic organization, so that although only a modest fraction of synapses express either NOS-I or sGC, NOS-positive PSDs are usually postsynaptic to sGC-positive axon terminals and vice versa.

\section{Methodological issues}

Many immunocytochemical studies have failed to detect NOS-I in hippocampal pyramidal neurons, notwithstanding reports suggesting that the antigen may be present (albeit at low levels) in these cells (Bredt et al., 1991; Chiang et al., 1994; Endoh et al., 1994; Wendland et al., 1994; Lin and Totterdell, 1998). The suggestion that NOS-III may be expressed by CA1 pyramidal neurons (Dinerman et al., 1994; O’Dell et al., 1994) has not been confirmed. We speculate that this finding may have arisen from cross-reacting antibodies, because: (1) other NOS-III antibodies fail to stain pyramidal cells, (2) when performed according to the protocol of Dinerman et al. (1994), NADPHd histochemical staining (which detects both NOS-I and NOS-III) stains pyramidal neurons of NOS-III knock-out mice (Weinberg et al. 1994), and (3) single-cell reverse-transcription PCR reveals a message for NOS-I but not NOS-III in pyramidal neurons (Chiang et al., 1994).

In contrast to the selective immunostaining of interneurons seen with traditional methods, we confirm previous reports that CA1 pyramidal cells stained for NOS-I after weak fixation (Wendland et al., 1994); moreover, our methods, which have been optimized to detect synaptic staining, reveal NOS-I in dendritic spines. Standard LM immunocytochemical methods may fail to reveal proteins known to concentrate at the PSD, whereas these apparently immunonegative synapses stain robustly after weak fixation or after proteolytic treatment (Watanabe et al., 1998; Burette et al., 1999; Fukaya and Watanabe, 2000; Burette et al., 2001b). We conclude that the highly concentrated protein matrix of the PSD blocks antibody access after the cross-linking induced by standard aldehyde fixation, in contrast to postembedding methods, which expose the entire surface of the section to antibody (Kellenberger and Hayat, 1991; Griffiths, 1993). Considering the biochemical evidence that NOS may be tightly complexed with other proteins, difficulties in detecting NOS-I at the synapse are not unexpected.

Several laboratories have reported that CA1 pyramidal neurons do not stain for NADPHd (Vincent and Kimura, 1992; Valtschanoff et al., 1993a). However, NADPHd staining requires subjective interpretation; pyramidal cell somata do stain if tissue is incubated long enough in the reaction medium (Weinberg et al., 1994). The difference in staining density with NADPHd in 
interneurons versus pyramidal neurons is so great that to obtain optimal staining in interneurons, one must stop the reaction before it reveals possible traces of NOS in pyramidal neurons. Notwithstanding the controversy about pyramidal cells, there is general agreement that the neuropil of the stratum radiatum is diff usely positive for NADPHd; in light of our results, this seems likely to represent synaptic staining. Because NADPHd may not stain NOS itself but instead a cofactor (e.g., tetrahydrobiopterin) (Reif et al., 1999; Pantke et al., 2001), we hypothesize that concentration of cofactor selectively in the neuropil may account for the apparent discrepancy.

\section{Supramolecular organization of the NO signaling pathway across the synapse}

Current evidence suggests a heterogeneous assembly of supramolecular complexes within the PSD (Nusser et al., 1994; Kharazia and Weinberg, 1997; Ottersen and Landsend, 1997; Kennedy, 2000; Husi and Grant, 2001). Immunogold EM demonstrates that NOS-I concentrates in the postsynaptic density in the neocortex, close to the NMDA receptor complex (Aoki et al., 1993, 1997, 1998; Valtschanoff and Weinberg, 2001), pointing to the importance of PSD-95 as a scaffold molecule helping to organize this signaling pathway (cf. Migaud et al., 1998; Sattler et al., 1999). Here we confirm the postsynaptic concentration of NOS-I in the stratum radiatum of CA1. Importantly, we also show that $\mathrm{sGC} \beta$ concentrates in terminals presynaptic to these NOS-I and NMDA receptor-expressing spines. Recent evidence suggests that $\mathrm{sGC} \beta$ may concentrate immediately subjacent to the plasma membrane also in non-neuronal tissues (Feussner et al., 2001; Zabel et al., 2002). We speculate that $\mathrm{sGC} \beta$ may interact with a presynaptic scaffold molecule anchored to the presynaptic plasma membrane (Russwurm et al., 2001).

The colocalization of NOS-I with NMDA receptors and PSD-95 demonstrated here is likely to reflect juxtaposition at the molecular scale (Brenman et al., 1996; Christopherson et al., 1999; Valtschanoff and Weinberg, 2001). We show that NOS concentrates at the PSD, whereas $\mathrm{sGC} \beta$ concentrates close to the plasma membrane of the presynaptic terminal. Although only $\sim 8-9 \%$ of synapses were immunopositive for each antigen, $>50 \%$ of those staining for NOS stained also for sGC and vice versa. Considering the technical limitations of our methods, the present results are likely to underestimate the true extent of this correspondence.

\section{A role for NO in retrograde signaling and synaptic plasticity?}

The relative functional significance of presynaptic and postsynaptic loci in mediation of LTP remains controversial; different subcellular loci may predominate under different experimental circumstances. The role of NO in hippocampal plasticity also remains controversial, with different groups reporting major effects, minor effects, no effects, or effects in some but not other experimental conditions. The most convincing experiments have been performed in models that may be far removed from the intact adult hippocampus. Based on current knowledge, a large number of distinct mechanisms might play a role in LTP (Sanes and Lichtman, 1999), but their relative contributions to synaptic plasticity in the adult brain remain to be established. Our data suggest that NO may mediate LTP in a specific subpopulation of CA1 synapses in the adult hippocampus.

A population of hippocampal interneurons expresses NOS-I throughout their cytoplasm. NO released by these interneurons seems poorly suited on anatomical grounds to mediate homosynaptic plasticity but might play a more global role (Gally et al., 1990; Valtschanoff et al., 1993b). Indeed, under some circumstances, synaptic potentiation can be diffuse (Bonhoeffer et al., 1989; Engert and Bonhoeffer, 1997), and experimental evidence suggests that NO may mediate diff use potentiation (Madison and Schuman, 1995), perhaps acting as a permissive signal. NO from these interneurons may also play a role in local regulation of blood flow, along with NO synthesized by NOS-III in the vascular endothelium (Loesch and Burnstock, 1996; Estrada and DeFelipe, 1998). Conversely, considering evidence from NOS-III knock-out mice (Son et al., 1996; Wilson et al., 1999), we speculate that NO synthesized in the local vascular endothelium may act as a region-specific permissive signal in some forms of synaptic plasticity.

Notwithstanding these possible diffuse effects, perhaps the most salient feature of synaptic plasticity in CA1 is its spatial precision; LTP in the Schaffer collateral pathway is widely believed to be predominantly homosynaptic. Thus, it seems puzzling that NO, a toxic and freely diffusible gas, could mediate this plasticity. We suggest that anatomical features of the signaling pathway may explain this apparent paradox. The concentration of material diffusing from a point source falls off rapidly with distance (Carslaw and Jaeger, 1959); because NO is unstable, its concentration will decline even more sharply. Thus, the spatial organization of NOS-I and $\mathrm{sGC} \beta$ in pyramidal neurons reported here could be expected to enhance transduction speed while keeping the retrograde signal focused on a single synapse.

\section{REFERENCES}

Aoki C, Fenstemaker S, Lubin M, Go CG (1993) Nitric oxide synthase in the visual cortex of monocular monkeys as revealed by light and electron microscopic immunocytochemistry. Brain Res 620:97-113.

Aoki C, Rhee J, Lubin M, Dawson TM (1997) NMDA-R1 subunit of the cerebral cortex co-localizes with neuronal nitric oxide synthase at preand postsynaptic sites and in spines. Brain Res 750:25-40.

Aoki C, Bredt DS, Fenstemaker S, Lubin M (1998) The subcellular distribution of nitric oxide synthase relative to the NR1 subunit of NMDA receptors in the cerebral cortex. Prog Brain Res 118:83-97.

Arancio O, Kiebler M, Lee CJ, Lev-Ram V, Tsien RY, Kandel ER, Hawkins RD (1996) Nitric oxide acts directly in the presynaptic neuron to produce long-term potentiation in cultured hippocampal neurons. Cell 87:1025-1035.

Arancio O, Antonova I, Gambaryan S, Lohmann SM, Wood JS, Lawrence DS, Hawkins RD (2001) Presynaptic role of cGMP-dependent protein kinase during long-lasting potentiation. J Neurosci 21:143-149.

Bazan NG, Packard MG, Teather L, Allan G (1997) Bioactive lipids in excitatory neurotransmission and neuronal plasticity. Neurochem Int 30:225-231.

Bliss TV, Collingridge GL (1993) A synaptic model of memory: longterm potentiation in the hippocampus. Nature 361:31-39.

Bonhoeffer T, Staiger V, Aertsen A (1989) Synaptic plasticity in rat hippocampal slice cultures: local "Hebbian" conjunction of pre- and postsynaptic stimulation leads to distributed synaptic enhancement. Proc Natl Acad Sci USA 86:8113-8117.

Boulton CL, Southam E, Garthwaite J (1995) Nitric oxide-dependent long-term potentiation is blocked by a specific inhibitor of soluble guanylyl cyclase. Neuroscience 69:699-703.

Bredt DS, Snyder SH (1994) Nitric oxide: a physiologic messenger molecule. Annu Rev Biochem 63:175-195.

Bredt DS, Glatt CE, Hwang PM, Fotuhi M, Dawson TM, Snyder SH (1991) Nitric oxide synthase protein and mRNA are discretely localized in neuronal populations of the mammalian CNS together with NADPH diaphorase. Neuron 7:615-624.

Brenman JE, Chao DS, Gee SH, McGee AW, Craven SE, Santillano DR, Wu Z, Huang F, Xia H, Peters MF, Froehner SC, Bredt DS (1996) Interaction of nitric oxide synthase with the postsynaptic density protein PSD-95 and $\alpha 1$-syntrophin mediated by PDZ domains. Cell 84:757-767.

Burette A, Wyszynski M, Valtschanoff JG, Sheng M, Weinberg RJ (1999) Characterization of glutamate receptor interacting proteinimmunopositive neurons in cerebellum and cerebral cortex of the albino rat. J Comp Neurol 411:601-612.

Burette A, Petrusz P, Schmidt HHHW, Weinberg RJ (2001a) Immuno- 
histochemical localization of nitric oxide synthase and soluble guanylyl cyclase in the ventral cochlear nucleus of the rat. J Comp Neurol 431:1-10.

Burette A, Khatri L, Wyszynski M, Sheng M, Ziff EB, Weinberg RJ (2001b) Differential cellular and subcellular localization of AMPA receptor-binding protein and glutamate receptor-interacting protein. J Neurosci 21:495-503.

Burgunder JM, Cheung PT (1994) Expression of soluble guanylyl cyclase gene in adult rat brain. Eur J Neurosci 6:211-217.

Carslaw HS, Jaeger JC (1959) Conduction of heat in solids, Ed 2. Oxford: Oxford UP.

Chiang LW, Schweizer FE, Tsien RW, Schulman H (1994) Nitric oxide synthase expression in single hippocampal neurons. Brain Res Mol Brain Res 27:183-188.

Choi S, Klingauf J, Tsien RW (2000) Postfusional regulation of cleft glutamate concentration during LTP at "silent synapses." Nat Neurosci 3:330-336.

Christopherson KS, Hillier BJ, Lim WA, Bredt DS (1999) PSD-95 assembles a ternary complex with the $N$-methyl-D-aspartic acid receptor and a bivalent neuronal NO synthase PDZ domain. J Biol Chem 274:27467-27473

Dawson TM, Bredt DS, Fotuhi M, Hwang PM, Snyder SH (1991) Nitric oxide synthase and neuronal NADPH diaphorase are identical in brain and peripheral tissues. Proc Natl Acad Sci USA 88:7797-7801.

Denninger JW, Marletta MA (1999) Guanylate cyclase and the NO/ cGMP signaling pathway. Biochim Biophys Acta 1411:334-350.

Derek JB, Hawkesb R, Bensona MA, Beesley PW (1999) Different dystrophin-like complexes are expressed in neurons and glia. J Cell Biol 147:645-658.

Devoto SH, Barnstable CJ (1989) Expression of the growth conespecific epitope CDA1 and the synaptic vesicle protein SVP38 in the developing mammalian cerebral cortex. J Comp Neurol 290:154-168.

Dinerman JL, Dawson TM, Schell MJ, Snowman A, Snyder SH (1994) Endothelial nitric oxide synthase localized to hippocampal pyramidal cells: implications for synaptic plasticity. Proc Natl Acad Sci USA 91:4214-4218.

Dun NJ, Dun SL, Wong RK, Forstermann U (1994) Colocalization of nitric oxide synthase and somatostatin immunoreactivity in rat dentate hilar neurons. Proc Natl Acad Sci USA 91:2955-2959.

Endoh M, Maiese K, Wagner JA (1994) Expression of the neural form of nitric oxide synthase by CA1 hippocampal neurons and other central nervous system neurons. Neuroscience 63:679-689.

Engert F, Bonhoeffer T (1997) Synapse specificity of long-term potentiation breaks down at short distances. Nature 388:279-284.

Estrada C, DeFelipe J (1998) Nitric oxide-producing neurons in the neocortex: morphological and functional relationship with intraparenchymal microvasculature. Cereb Cortex 8:193-203.

Faber-Zuschratter H, Wolf G (1994) Ultrastructural distribution of NADPH-diaphorase in cortical synapses. NeuroReport 5:2029-2032.

Faber-Zuschratter H, Seidenbecher T, Reymann K, Wolf G (1996) Ultrastructural distribution of NADPH-diaphorase in the normal hippocampus and after long-term potentiation. J Neural Transm 103:807-817.

Feussner M, Richter H, Baum O, Gossrau R (2001) Association of soluble guanylate cyclase with the sarcolemma of mammalian skeletal muscle fibers. Acta Histochem 103:265-277.

Forstermann U, Schmidt HHHW, Pollock JS, Sheng H, Mitchell JA, Warner TD, Nakane M, Murad F (1991) Isoforms of nitric oxide synthase. Characterization and purification from different cell types. Biochem Pharmacol 42:1849-1857.

Fukaya M, Watanabe M (2000) Improved immunohistochemical detection of postsynaptically located PSD-95/SAP90 protein family by protease section pretreatment: a study in the adult mouse brain. J Comp Neurol 426:572-586

Gally JA, Montague PR, Reeke GN, Edelman GM (1990) The NO hypothesis: possible effects of a short-lived, rapidly diff usible signal in the development and function of the nervous system. Proc Natl Acad Sci USA 87:3547-3551.

Ganguly K, Kiss L, Poo M (2000) Enhancement of presynaptic neuronal excitability by correlated presynaptic and postsynaptic spiking. Nat Neurosci 3:1018-1026.

Gibb BJ, Garthwaite J (2001) Subunits of the nitric oxide receptor, soluble guanylyl cyclase, expressed in rat brain. Eur J Neurosci 13:539-544.

Gonzalez-Hernandez T, Perez de la Cruz MA, Mantolan-Sarmiento B (1996) Histochemical and immunohistochemical detection of neurons that produce nitric oxide: effect of different fixative parameters and immunoreactivity against non-neuronal NOS antisera. J Histochem Cytochem 44:1399-1413.

Griffiths G (1993) Fine structure immunocytochemistry. Berlin: Springer.

Haley JE (1998) Gases as neurotransmitters. Essays Biochem 33:79-91.

Haley JE, Schaible E, Pavlidis P, Murdock A, Madison DV (1996) Basal and apical synapses of CA1 pyramidal cells employ different LTP induction mechanisms. Learn Mem 3:289-295.
Hawkins RD, Son H, Arancio O (1998) Nitric oxide as a retrograde messenger during long-term potentiation in hippocampus. Prog Brain Res 118:155-172.

Holscher C (1997) Nitric oxide, the enigmatic neuronal messenger: its role in synaptic plasticity. Trends Neurosci 20:298-303

Hope BT, Michael GJ, Knigge KM, Vincent SR (1991) Neuronal NADPH diaphorase is a nitric oxide synthase. Proc Natl Acad Sci USA 88:2811-2814.

Husi H, Grant SG (2001) Isolation of 2000-kDa complexes of $N$-methylD-aspartate receptor and postsynaptic density 95 from mouse brain. J Neurochem 77:281-291.

Ibarra C, Nedvetsky PI, Gerlach M, Riederer P, Schmidt HHHW (2001) Regional and age-dependent expression of the nitric oxide receptor, soluble guanylyl cyclase, in the human brain. Brain Res 907:54-60.

Kellenberger E, Hayat MA (1991) Some basic concepts for the choice of methods. In: Colloidal gold: principles, methods, and applications (Hayat MA, ed), pp 1-30. San Diego: Academic.

Kennedy MB (2000) Signal-processing machines at the postsynaptic density. Science 290:750-754.

Kharazia VN, Weinberg RJ (1997) Tangential synaptic distribution of NMDA and AMPA receptors in rat neocortex. Neurosci Lett 238:41-44.

Kiedrowski L, Costa E, Wroblewski JT (1992) Glutamate receptor agonists stimulate nitric oxide synthase in primary cultures of cerebellar granule cells. J Neurochem 58:335-341.

Koesling D (1999) Studying the structure and regulation of soluble guanylyl cyclase. Methods 19:485-493.

Lin H, Totterdell S (1998) Light and electron microscopic study of neuronal nitric oxide synthase-immunoreactive neurons in the rat subiculum. J Comp Neurol 395:195-208.

Loesch A, Burnstock G (1996) Ultrastructural study of perivascular nerve fibres and endothelial cells of the rat basilar artery immunolabelled with monoclonal antibodies to neuronal and endothelial nitric oxide synthase. J Neurocytol 25:525-534.

Lu YF, Kandel ER, Hawkins RD (1999) Nitric oxide signaling contributes to late-phase LTP and CREB phosphorylation in the hippocampus. J Neurosci 19:10250-10261.

Madison DV, Schuman EM (1995) Diffusible messengers and intercellular signaling: locally distributed synaptic potentiation in the hippocampus. Curr Top Microbiol Immunol 196:5-6.

Malenka RC, Nicoll RA (1999) Long-term potentiation-a decade of progress? Science 285:1870-1874.

Malgaroli A, Ting AE, Wendland B, Bergamaschi A, Villa A, Tsien RW, Scheller RH (1995) Presynaptic component of long-term potentiation visualized at individual hippocampal synapses. Science 268:1624-1628.

Malinow R, Mainen ZF, Hayashi Y (2000) LTP mechanisms: from silence to four-lane traffic. Curr Opin Neurobiol 10:352-357.

Matsuoka I, Giuili G, Poyard M, Stengel D, Parma J, Guellaen G, Hanoune J (1992) Localization of adenylyl and guanylyl cyclase in rat brain by in situ hybridization: comparison with calmodulin mRNA distribution. J Neurosci 12:3350-3360.

Migaud M, Charlesworth P, Dempster M, Webster LC, Watabe AM, Makhinson M, He Y, Ramsay MF, Morris RG, Morrison JH, O'Dell TJ, Grant SG (1998) Enhanced long-term potentiation and impaired learning in mice with mutant postsynaptic density-95 protein. Nature 396:433-439.

Moncada S, Palmer RM, Higgs EA (1991) Nitric oxide: physiology, pathophysiology, and pharmacology. Pharmacol Rev 43:109-142.

Nicoll RA, Malenka RC (1995) Contrasting properties of two forms of long-term potentiation in the hippocampus. Nature 377:115-118.

Nusser Z, Mulvihill E, Streit P, Somogyi P (1994) Subsynaptic segregation of metabotropic and ionotropic glutamate receptors as revealed by immunogold localization. Neuroscience 61:421-427.

O’Dell TJ, Huang PL, Dawson TM, Dinerman JL, Snyder SH, Kandel ER, Fishman MC (1994) Endothelial NOS and the blockade of LTP by NOS inhibitors in mice lacking neuronal NOS. Science 265:542-546.

Ottersen OP, Landsend AS (1997) Organization of glutamate receptors at the synapse. Eur J Neurosci 9:2219-2224

Pantke MM, Reif A, Valtschanoff JG, Shutenko Z, Frey A, Weinberg RJ, Pfleiderer W, Schmidt HHHW (2001) Pterin interactions with distinct reductase activities of NO synthase. Biochem J 356:43-51.

Petralia RS, Wang YX, Wenthold RJ (1994) The NMDA receptor subunits NR2A and NR2B show histological and ultrastructural localization patterns similar to those of NR1. J Neurosci 14:6102-6120.

Phend KD, Weinberg RJ, Rustioni A (1992) Techniques to optimize post-embedding single and double staining for amino acid neurotransmitters. J Histochem Cytochem 40:1011-1020.

Phend KD, Rustioni A, Weinberg RJ (1995) An osmium-free method of epon embedment that preserves both ultrastructure and antigenicity for post-embedding immunocytochemistry. J Histochem Cytochem 43:283-292.

Prast H, Philippu A (2001) Nitric oxide as modulator of neuronal function. Prog Neurobiol 64:51-68.

Reif A, Frohlich LG, Kotsonis P, Frey A, Bommel HM, Wink DA, Pfleiderer W, Schmidt HHHW (1999) Tetrahydrobiopterin inhibits 
monomerization and is consumed during catalysis in neuronal NO synthase. J Biol Chem 274:24921-24929.

Russwurm M, Wittau N, Koesling D (2001) Guanylyl cyclase/PSD-95 interaction: targeting of the nitric oxide-sensitive $\alpha_{2} \beta_{1}$ guanylyl cyclase to synaptic membranes. J Biol Chem 276:44647-44652.

Sancesario G, Morello M, Reiner A, Giacomini P, Massa R, Schoen S, Bernardi G (2000) Nitrergic neurons make synapses on dual-input dendritic spines of neurons in the cerebral cortex and the striatum of the rat: implication for a postsynaptic action of nitric oxide. Neuroscience 99:627-642.

Sanes JR, Lichtman JW (1999) Can molecules explain long-term potentiation? Nat Neurosci 2:597-604.

Sattler R, Xiong Z, Lu WY, Hafner M, MacDonald JF, Tymianski M (1999) Specific coupling of NMDA receptor activation to nitric oxide neurotoxicity by PSD-95 protein. Science 284:1845-1848.

Schmidt HHHW, Gagne GD, Nakane M, Pollock JS, Miller MF, Murad F (1992) Mapping of neural nitric oxide synthase in the rat suggests frequent co-localization with NADPH diaphorase but not with soluble guanylyl cyclase and novel paraneural functions for nitrinergic signal transduction. J Histochem Cytochem 40:1439-1456.

Schuman EM (1997) Synapse specificity and long-term information storage. Neuron 18:339-342.

Sheng M, Lee SH (2001) AMPA receptor trafficking and the control of synaptic transmission. Cell 105:825-828.

Shindler KS, Roth KA (1996) Double immunofluorescent staining using two unconjugated primary antisera raised in the same species. J Histochem Cytochem 44:1331-1335.

Soderling TR, Derkach VA (2000) Postsynaptic protein phosphorylation and LTP. Trends Neurosci 23:75-80.

Son H, Hawkins RD, Martin K, Kiebler M, Huang PL, Fishman MC, Kandel ER (1996) Long-term potentiation is reduced in mice that are doubly mutant in endothelial and neuronal nitric oxide synthase. Cell 87:1015-1023.

Son H, Lu YF, Zhuo M, Arancio O, Kandel ER, Hawkins RD (1998) The specific role of cGMP in hippocampal LTP. Learn Mem 5:231-245.

Stevens CF, Wang Y (1994) Changes in reliability of synaptic function as a mechanism for plasticity. Nature 371:704-707.

Tochio H, Mok YK, Zhang O, Kan HM, Bredt DS, Zhang M (2000) Formation of nNOS/PSD-95 PDZ dimer requires a preformed betafinger structure from the nNOS PDZ domain. J Mol Biol 303:359-370.

Valtschanoff JG, Weinberg RJ (2001) Laminar organization of the NMDA receptor complex within the postsynaptic density. J Neurosci 21:1211-1217.

Valtschanoff JG, Weinberg RJ, Kharazia VN, Nakane M, Schmidt
HHHW (1993a) Neurons in rat hippocampus that synthesize nitric oxide. J Comp Neurol 331:111-121.

Valtschanoff JG, Weinberg RJ, Kharazia VN, Schmidt HHHW, Nakane M, Rustioni A (1993b) Neurons in rat cerebral cortex that synthesize nitric oxide: NADPH diaphorase histochemistry, NOS immunocytochemistry, and colocalization with GABA. Neurosci Lett 157:157-161.

Valtschanoff JG, Burette A, Wenthold RJ, Weinberg RJ (1999) Expression of NR2 receptor subunit in rat somatic sensory cortex: synaptic distribution and colocalization with NR1 and PSD-95. J Comp Neurol 410:599-611.

Valtschanoff JG, Burette A, Davare MA, Leonard S, Hell JW, Weinberg RJ (2000) SAP97 concentrates at the postsynaptic density in cerebral cortex. Eur J Neurosci 12:3605-3614.

Vincent SR, Kimura H (1992) Histochemical mapping of nitric oxide synthase in the rat brain. Neuroscience 46:755-784.

Watanabe M, Fukaya M, Sakimura K, Manabe T, Mishina M, Inoue Y (1998) Selective scarcity of NMDA receptor channel subunits in the stratum lucidum (mossy fibre-recipient layer) of the mouse hippocampal CA3 subfield. Eur J Neurosci 10:478-487.

Wedel B, Garbers D (2001) The guanylyl cyclase family at Y2K. Annu Rev Physiol 63:215-233.

Weinberg RJ, Valtschanoff JG, Kharazia VN, Schmidt HHHW (1994) Further anatomical study of NOS in rat hippocampus. Soc Neurosci Abstr 20:445.

Wendland B, Schweizer FE, Ryan TA, Nakane M, Murad F, Scheller RH, Tsien RW (1994) Existence of nitric oxide synthase in rat hippocampal pyramidal cells. Proc Natl Acad Sci USA 91:2151-2155.

Wilson RI, Godecke A, Brown RE, Schrader J, Haas HL (1999) Mice deficient in endothelial nitric oxide synthase exhibit a selective deficit in hippocampal long-term potentiation. Neuroscience 90:1157-1165.

Zabel U, Weeger M, La M, Schmidt HHHW (1998) Human soluble guanylate cyclase: functional expression and revised isoenzyme family. Biochem J 335:51-57.

Zabel U, Hausler C, Weeger M, Schmidt HHHW (1999) Homodimerization of soluble guanylyl cyclase subunits. Dimerization analysis using a glutathione $S$-transferase affinity tag. J Biol Chem 274:18149-18152.

Zabel U, Kleinschnitz C, Oh P, Nedvetsky P, Smolenski A, Muller H, Kronich P, Kugler P, Walter U, Schnitzer JE, Schmidt HHHW (2002) Calcium-dependent membrane association sensitizes soluble guanylyl cyclase to nitric oxide. Nat Cell Biol 4:307-311.

Zakharenko SS, Zablow L, Siegelbaum SA (2001) Visualization of changes in presynaptic function during long-term synaptic plasticity. Nat Neurosci 4:711-717.

Zorumski CF, Izumi Y (1998) Modulation of LTP induction by NMDA receptor activation and nitric oxide release. Prog Brain Res 118:173182. 